\title{
Pieza cúbica Celtibérica de arcilla hallada en Sepúlveda (Segovia)
}

Juan Fco. Blanco García

Universidad Autónoma de Madrid

\section{Resumen}

Entre los muchos y variados objetos singulares celtibéricos elaborados en cerámica, los dados o piezas cúbicas constituyen una rareza extrema. En estas páginas vamos a dar a conocer un cubo hallado en Sepúlveda cuya mayor peculiaridad es la rica y variada ornamentación que presentan sus caras. Son varias las opciones interpretativas que pueden barajarse en cuanto a su posible funcionalidad. La iconografía desarrollada en sus caras y la secuencia histórica documentada en el yacimiento nos permiten proponer una datación probable de finales del siglo I a. C.

Palabras clave: Edad del Hierro, valle del Duero, cerámica celtibérica, iconografía.

\section{Abstract}

In the repertory of the Celtiberian singulars clay productions, the cubes or dice are very rares. In this paper we are going to study a cubic object from the archaeological site of Sepúlveda, very rich decorated in each side. Its not clear the function of this original piece and by this reason we must contemplated different options. The peculiar iconography (with geometric and zoomorphic motifs) engraved in the six sides, and the general datation of the settlement suggest a chronology of late 1 st century B.C.

Keywords: Iron Age, Duero Valley, celtiberian pottery, iconography.

A pesar de que fue en febrero de 1968 cuando vi por primera vez a Charo, momento en el que, como un curioso más, me acerqué en varias ocasiones a las excavaciones que estaba llevando a cabo en la necrópolis de El Cantosal (Coca, Segovia), hasta 1978 no empece a conocerla un poco más de cerca. Entre los muchos méritos que engalanaron su actividad profesional, siempre superados por los que atesoraba en sus relaciones con cuantos le rodeaban, uno de los que más le tenemos que agradecer quienes estamos ligados a la arqueología segoviana es el de haber realizado sustanciosas aportaciones a la misma desde aquella lejana década de los sesenta del pasado siglo hasta fechas tan recientes como el año 2003. Por ello, en su recuerdo, tan querido como indeleble, he creído apropiado dar a conocer un interesante hallazgo procedente de la zona segoviana que más a fondo ella conocía: una pieza cúbica de arcilla que añade nuevos datos sobre los zoomorfos celtibéricos representados en perspectiva cenital.

A raíz de la publicación de un trabajo nuestro sobre la Edad del Hierro en Sepúlveda, efectuado con los datos y materiales disponibles hasta el momento y a los que se añadió una colección particular que nos fue brindada para su estudio (Blanco García, 1998), nuevos hallazgos procedentes del mismo lugar han llegado a nuestro conocimiento que nos parece necesario dar a conocer para enriquecer el panorama presentado en aquella ocasión. Entre ellos, destacamos una excelente pieza cúbica fabricada en cerámica fina cada una de cuyas seis caras ha sido objeto de una decoración diferente y original. El hallazgo se produjo hace años en la superficie del 
Cerro de Somosierra, en un punto indeterminado que se sitúa entre el actual cementerio de Sepúlveda y la arruinada iglesia de San Juan ${ }^{1}$. Un medio arqueológico, por tanto, de carácter habitacional, pues es en todo este área en el que se localizan los restos del poblado de la Edad del Hierro hoy muy destruidos por el secular laboreo agrícola y la erosión. Al ser una pieza descontextualizada, la aproximación funcional $\mathrm{y}$ cronológica han de basarse tanto en las características intrínsecas de la misma como en la documentación general del yacimiento con la que contamos y en los datos que nos ofrecen otros lugares arqueológicos.

\section{1.- DESCRIPCIÓN.}

Cocido en atmósfera oxidante, el cubo cerámico ha sido elaborado en una arcilla muy depurada, compacta y dura en la que no son perceptibles a simple vista los degrasantes, tal como puede apreciarse a través de varias roturas que posee. Es, por tanto, la característica masa arcillosa en la que habitualmente se fabrican las cajitas excisas, los pies votivos, gran parte de figurillas zoomorfas y otras muchas producciones singulares celtibéricas de calidad, sean macizas o de paredes gruesas. A pesar de ser este un producto elaborado con esmero, quien lo modeló no ha conseguido una forma perfectamente cúbica, pues cada una de sus caras no tiene las mismas dimensiones de largo que de ancho y esto significa que según sobre qué cara hagamos posar la pieza se nos muestra ligeramente inclinada hacia un lado u otro. Es más, se puede decir que cada cara tiene dos dimensiones de largo y otras dos de ancho, según por qué extremo se mida, lo que hace más perceptible su relativa irregularidad. En este punto conviene decir que para mejor describir la pieza se ha denominado a cada una de sus seis caras con letras, de la $\mathrm{A}$ a la F (Figura 1), y que es en la cara $\mathrm{A}$ en la que hallamos la máxima diferencia en sus dimensiones, pues su longitud oscila entre 41 y $43 \mathrm{~mm}$ de un extremo al opuesto mientras que su anchura varía de los 35 a los $37 \mathrm{~mm}$. La más regular es la cara D, cuyas longitudes y anchuras apenas se desvían de los $38 \mathrm{~mm}$. Las medidas de las restantes caras se sitúan siempre entre los 35 y los $43 \mathrm{~mm}$, lo que de interpretar la pieza como dado de juego -cuestión que presenta más de un problema, como más adelante veremos-, significa que estamos ante un dado de tamaño anormalmente grande, pues los conocidos tanto en el mundo celtibérico

1 Agradecemos a Dña A. Rico Francia las facilidades que nos ha dado para documentar la pieza y su loable interés como en el griego, púnico, etrusco, galo o romano suelen ser de dimensiones menores, si exceptuamos algunas raros ejemplares que pueden llegar a medir hasta $164 \mathrm{~mm}$ de lado (Béal, 1983, 353-354, nn. 1290 y 1296), o los dados rectangulares, tales como el exhumado en el compartimento 102 del Tossal de Sant Miquel de Llíria, que mide 46 x 33 mm (Bonet Rosado, 1995, 243 n. 0387 y 484, fig. 119 n. 0387-D 102), o el que se halló hace unos años en la zona de Nimes, fechado a finales del Hierro II (Py, 1990, 459, doc. 112 n. 23). Este hecho, unido a la existencia de sendas perforaciones que afectan a tres de sus caras, nos hicieron plantearnos momentáneamente la posibilidad de que se tratara de una pesa o fusayola más que de un dado de juego. Sin embargo, la estrechez de los orificios, el que cada cara estuviera ricamente decorada con un motivo diferente $\mathrm{y}$ el haber matado las aristas mediante bisel parecían sugerir que la función del objeto era muy distinta a la de servir de simple tensador.

Esto último, el que todos los cantos hayan sido biselados, es una circunstancia que de interpretar el cubo como dado de juego nos podría hacer pensar en que quizá el objeto de este redondeamiento hubiera sido el de conseguir que una vez hubiera sido lanzado pudiera rodar por el suelo con mayor soltura y libertad. Sin embargo, incluso conviniendo en que pudiera haber sido esa su funcionalidad esta explicación práctica del biselado es también cuestionable, pues son muchas las cajitas excisas, pies votivos, y otras piezas singulares cuyas aristas han sido matadas por el mismo procedimiento y su función nada tiene que ver con que estuvieran destinadas a rodar por un plano horizontal.

Como acabamos de decir, las dos finas perforaciones de sección circular cuya funcionalidad no parece ser otra que la de poder suspender el objeto mediante una delgada cuerda que se hiciera pasar por ellas son elementos absolutamente infrecuentes en los dados de cualquier época hasta ahora conocidos. A juzgar por las rebabas aún visibles y por el lugar en el que se localizan tales horadaciones, ambas han sido practicadas una vez terminada de decorar la pieza pero antes de haber sido cocida. La primera, que se conserva intacta y posee una sección de $2 \mathrm{~mm}$ de diámetro, se ha practicado desde el centro del lateral derecho de la cara $\mathrm{C}$ hasta el fondo de la excisión triédrica localizada en el centro del lateral izquierdo de la cara D. Analizada con detenimiento esta perforación, no hemos observado ni 
marcas de rozadura de la posible cuerda que en su día pudo haberla atravesado ni restos de algún tipo de óxido que indicara que el material que la recorría fuera hilo metálico o fina cadeneta. De la segunda perforación es plenamente visible el recorrido íntegro del canal puesto que una de las roturas de la pieza se encuentra en este punto, habiendo quedado al aire el mismo en toda su longitud. Por la forma de dicha rotura da la impresión de que se ha producido al introducir un objeto extraño en la perforación, una cuerda tal vez, de la que después se ha tirado fuertemente, arrancando parte de la arcilla que forma el cuerpo del dado. Esta perforación se efectuó desde el centro del lateral inferior de la cara D hasta el centro del lateral derecho de la cara E, siendo tanto el inicio como el final de la misma el fondo de sendas excisiones triédricas. Si una idea parece claramente desprenderse de la existencia de estos dos orificios es que el poseedor de la pieza debía de sentir gran aprecio por ella. Tanto como para no tenerla tirada por cualquier sitio cuando no estaba siendo utilizada sino suspendida de algún lugar concreto y cercano de si. No sería extraño tampoco que este cubo formara conjunto con otros de sus mismas características físicas e iconográficas (pues sabemos que en las tiradas de dados siempre se empleaban dos o tres unidades), y todos estuvieran ensartados con la misma cuerda para que no se extraviaran.

Las superficies de todo el cubo han sido tratadas mediante un cuidadoso alisado, llegando casi al bruñido, para después recibir una rica y variada decoración realizada tanto con técnica exclusivamente incisa (caras A y B) como excisa (cara E) o combinando ambas (caras C, D y F). Las incisiones, todas ellas simples, han sido realizadas con dos tipos de instrumentos apuntados: uno de punta muy aguzada con el que se han conseguido trazos estrechos y limpios (caras $\mathrm{C}$ y D), y otro de punta ancha que más que incisiones lo que realmente deja son surcos de dos estrechas caras convergentes en profundidad como si de finas excisiones diédricas se tratara. Las excisiones están realizadas bien en basto (centro de la cara F) bien a bisel (diédrico, triédrico y tetraédrico), con caras tanto rectas como curvas en las extracciones efectuadas por este segundo procedimiento.

Geométrica o figurativa, cada cara posee una decoración diferente, algunas habituales en diversos productos artesanales celtibéricos, como más adelante tendremos ocasión de ver, pero

2 Únicamente en una copa de Numancia encontramos un grafito que, siquiera lejanamente, recuerda este entrama- otras bastante originales. En la cara A encontramos un aspa de doble trazo en cada uno de cuyos ángulos se dispone un arco de círculo que se abre al exterior respecto a la clave del aspa y dos trazos paralelos, a modo de radios, que parten con dirección al hipotético centro de cada círculo. Todo ello está realizado con incisión ancha efectuada con un punzón grueso que ha dejado trazos compuestos por dos estrechas caras que convergen en profundidad.

En la cara B, y también conseguido a base de idéntico tipo de incisiones, tenemos un motivo iconográfico tan original y extraño a la cultura celtibérica que no hallamos paralelos para él en ningún otro objeto de su filiación ${ }^{2}$. En perfecta simetría contrapuesta, y tomando como ejes una cruz central de brazos iguales, se han grabado una serie de líneas rectas y curvas de trazo tan firme que parece claro que no se hicieron al azar, que se sabía perfectamente lo que se quería dibujar. Realmente no sabemos si lo representado es un motivo de carácter geométrico o figurativo, pues, por una parte, parece un geometrismo sin mayor trascendencia pero, por otra, el mismo se asemeja a especies de hachas contrapuestas de una sola boca disimétrica.

En la cara $\mathrm{C}$ hallamos un ejemplo más de representación zoomorfa en perspectiva cenital cuyo acusado esquematismo no nos resulta extraño en este tipo de imágenes porque conocemos casos similares. Realizado el contorno con doble línea incisa paralela, el interior adquiere cuerpo mediante una serie de cortos trazos también incisos que se disponen oblicuamente respecto a los que delimitan aquél. Mientras en cada una de las extremidades estos trazos internos se disponen a distancias casi regulares y todos ellos mantienen la misma orientación (excepto en el extremo distal de la inferior derecha), los que rellenan el cuerpo de la imagen forman tripletas de direcciones alternantes. Tripletas que, habida cuenta la fuerte tendencia a la triplicidad que nos muestra el arte de las poblaciones célticas, no creemos gratuitas sino totalmente intencionales. Las líneas de contorno tanto del cuerpo como de las extremidades superior izquierda e inferior derecha en sus extremos permanecen abiertas. Es decir, no han sido cerradas mediante el dibujo de la cabeza, el rabo o los dedos y garras del animal, como observamos en otras representaciones análogas. Solamente el extremo distal de las extremidades superior derecha e inferior izquierda cierran pero por confluencia simple de las líneas delimitativas.

do de trazos (Wattenberg Sanpere, 1963: 185, n. 747, tab. XXVI, n. 747). 
A derecha e izquierda enmarcan la figura dos arcos de círculo contrapuestos entre si que se abren hacia la parte opuesta al zoomorfo descrito. Igualmente están realizados con doble línea incisa sus contornos, también quedan abiertos en los extremos y sus interiores aparecen rellenos con trazos dobles de dirección alterna. Cada uno de los pequeños espacios libres que median entre la figura y los referidos arcos ha recibido una decoración complementaria efectuada con técnica excisa a bisel: triédrica junto a cada una de las extremidades del zoomorfo y tetraédrica a ambos lados del tórax de la imagen. La descripción de esta cara $\mathrm{C}$ quedaría completa señalando la existencia de una perforación que parte del centro de su lateral derecho, como ya hemos indicado más arriba, y cala hasta la D.

En esta cara D también se combina la decoración incisa con la excisa a bisel. A partir de una doble aspa central se ha diseñado una flor tetrapétala de proporciones equilibradas, superficies planas y trazo firme, toda ella realizada con la primera de las técnicas mencionadas. Para contrarrestar la planitud de los pétalos lanceolados y dotar de mayor volumen y realce a la flor, entre cada uno de ellos se ha dispuesto un triedro exciso cuyas dos caras curvas se adaptan a las parábolas de las hojas y la recta al lateral del cubo. A esta cara $\mathrm{D}$ vienen a desembocar dos perforaciones. Por un lado, la que veíamos partía del centro del lateral derecho de la cara $\mathrm{C}$ sale al fondo del triedro exciso del lateral izquierdo de esta cara D. Por otro, en la excisión triédrica inferior de esta cara se practicó otra horadación que iba a dar a la ubicada en el lateral derecho de la cara E. Es este segundo orificio el que se encuentra al aire, resultando visible en todo su recorrido por haber sido arrancada parte de la pasta existente en este lateral.

La cara E, la más deteriorada de las seis, también ha sido decorada con una flor tetrapétala, pero a diferencia de la anteriormente referida ésta no es de superficies planas sino que está labrada íntegramente en relieve por medio de la técnica excisa a bisel. Cada uno de los pétalos lanceolados lo conforman una especie de grueso nervio central en positivo que se dispone entre dos zonas deprimidas y todo ello en perfecta simetría. Nuevamente es un triedro exciso (de dos caras igualmente curvas y una recta, según a qué parte hayan de adaptarse) dispuesto entre cada pétalo el que da mayor volumen a la flor.

Para finalizar, en la cara $\mathrm{F}$ se ha dispuesto una decoración en parte similar a la que veíamos en la cara A. Con una doble aspa central realizada con incisión gruesa como motivo central -y cuya clave cuadrada ha sido vaciada por excisión en basto-, en cada uno de los ángulos de la misma se ha dispuesto un arco de círculo también inciso y abierto hacia el exterior, en dirección opuesta al centro del aspa. Cada uno de estos arcos cobija una especie de creciente exciso diédrico realizado a bisel que se abre también hacia el exterior.

Desde el punto de vista de la conservación, aunque en general su estado es relativamente bueno, cuatro de sus caras muestran pérdida de masa arcillosa provocada por haber recibido fuertes golpes. Golpes que quizá se produjeran cuando la pieza estaba en pleno uso -como parecen indicar las erosionadas aristas resultantes-, con lo que quedaría inservible para desempeñar la función para la que fue creada, si admitimos que esta tuviera que ver con el juego, la adivinación o cualquier otra actividad en la que puedan darse varias alternativas, positivas unas y negativas otras. Muestra, asimismo, de que durante cierto tiempo este cubo estuvo en uso son las múltiples rozaduras antiguas que se pueden ver tanto en sus caras como en sus suavizados cantos.

\section{2.- CONSIDERACIONES SOBRE SU ICONOGRA-} FÍA, FUNCIONALIDAD Y CRONOLOGÍA.

Puesto que algunos aspectos relativos a estas cuestiones ya han sido adelantados al describir la pieza, no vamos a volver sobre ellos en este apartado a no ser que sea necesario para cimentar alguna idea. Ciertamente estamos ante una pieza excepcional, no sólo en lo que se refiere a su originalidad y posible funcionalidad dentro del variado elenco de las producciones cerámicas singulares celtibéricas, sino también en cuanto a la rica ornamentación con la que ha sido engalanada. Sin embargo, su hallazgo fuera de contexto, el carácter de unicum que por ahora tiene tanto en la Meseta prerromana como en el ámbito cultural ibérico y los limitados conocimientos que poseemos sobre las posibles actividades con las que cabría relacionar este objeto (sellado de objetos, juego, prácticas mágicas o adivinatorias, etc.), hipotecan seriamente cualquier intento de acercamiento al significado que tuvo. Ni siquiera sabemos si la pieza era única para la función que debió de desempeñar o formó parte de un conjunto, de un grupo de dados (todos con las mismas representaciones que éste en sus caras o, más improbablemente, diferentes) de los que sólo éste ha llegado hasta nosotros.

El repertorio de decoraciones desarrollado es bien conocido en la plástica celtibérica, excepción hecha de la representación que vemos en la cara B. Cada lado muestra un motivo caracterizado por la total adaptación al campo decorativo, la simetría y la geometrización de lo representado cuando se trata de imágenes figurativas, 


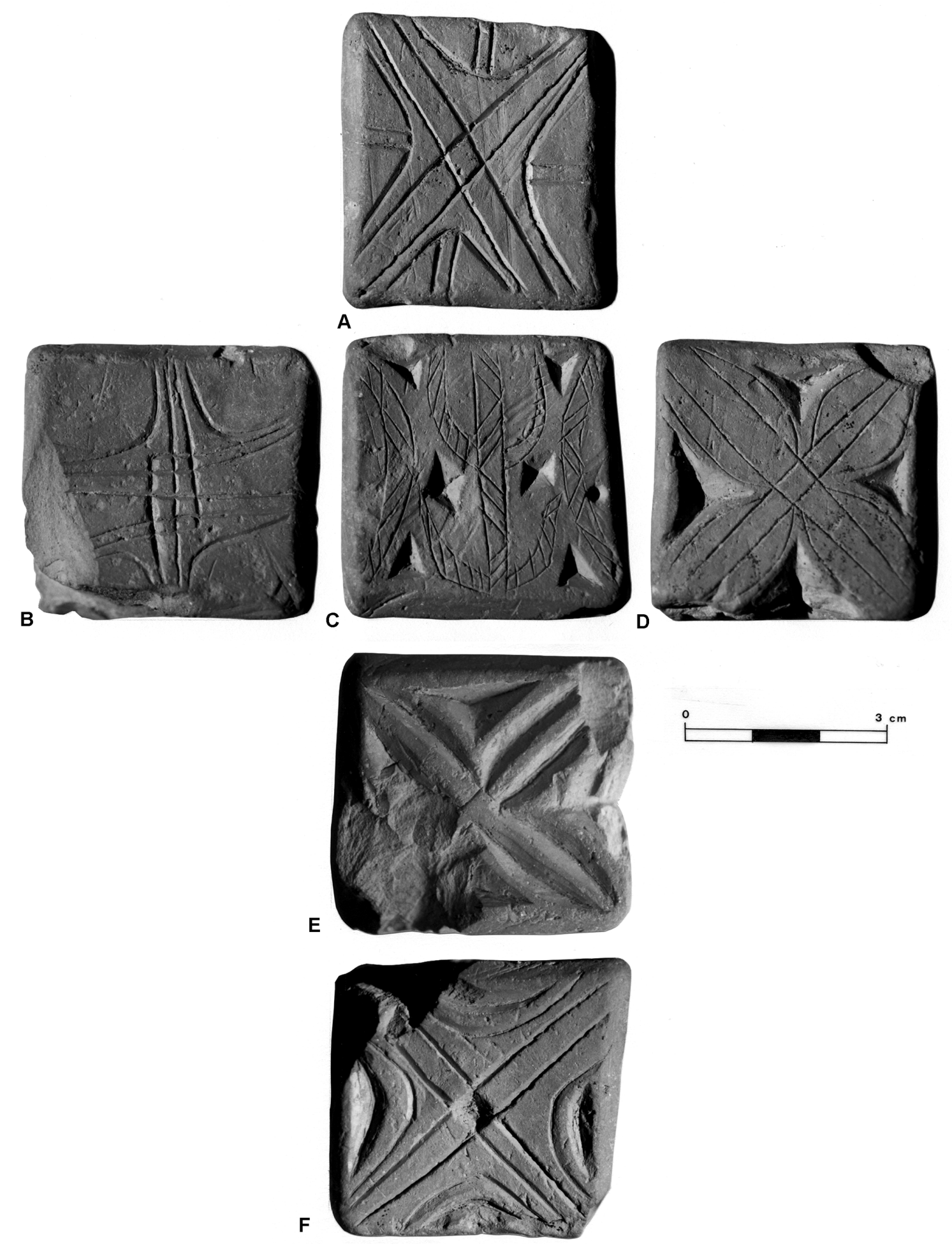

Figura 1. Dado de Sepúlveda (Fotografias:J. F. Blanco García). 
notas muy propias del arte de los pueblos prerromanos del interior peninsular. Mientras en las caras A, B y F se han desarrollado decoraciones geométricas, las $\mathrm{C}, \mathrm{D}$ y $\mathrm{E}$ se han individualizado con figuraciones esquematizadas, las dos últimas florales y la primera mediante un zoomorfo en perspectiva cenital muy típico de los ámbitos celtibérico y vacceo. Nada tiene de extraño la enorme economía de rasgos de la que se ha hecho uso en esta imagen de cuadrúpedo, pues son varios los ejemplares conocidos que presentan una simplicidad parecida e incluso mayor (p. ej., Romero y Sanz, 1992, 456, fig. $1 \mathrm{n}^{\mathrm{o}} 4$; Sanz Mínguez, 1997, 148, fig. $150 \mathrm{n}^{\circ}$ 139, también 194, fig. 182 $\mathrm{n}^{\mathrm{o}} 724$ y 463 , XXXII). Tampoco es raro el relleno interior del cuerpo con grupos de tres incisiones en contrapuesta oblicuidad respecto a las líneas del contorno, pues en los zoomorfos laterales grabados en el reverso del pomo del puñal recuperado en la sepultura 32 de la necrópolis vallisoletana de Las Ruedas hallamos sus interiores también rellenos de grupos de tres líneas (aunque algunos son de dos y de cuatro) dando cuerpo a las respectivas imágenes (Sanz Mínguez, 1997, 87, fig. 77 y XXX). Puesto que en el simbolismo céltico, el tres era un número sagrado y en la triplicidad estos pueblos veían la fórmula adecuada para la intensificación de cuanto de bueno pudiera haber en las divinidades y en las cosas (Green, 1989, 204-205; Ead., 1997, 214-216), lo lógico es pensar que estas representaciones zoomorfas eran portadoras de dones o contenidos positivos para el ser humano, bien en la guerra (puñal de Las Ruedas), en el juego o la magia (dado de Sepúlveda), en la protección personal (broche de Arrabalde 2, Delibes y Esparza, 1989, 123, fot. p. 128; Romero y Sanz, 1992, 462, fig. 2, 21), o incluso en la producción y la alimentación (gran vaso de almacenaje de Roa, Abarquero Moras, 2002; tapadera de boca de horno doméstico de Las Quintanas, Centeno et alii, 2003, 80, figs. 5, 7 y 10).

Por lo que se refiere a la funcionalidad de la pieza, al menos caben cuatro posibilidades: que fuera un objeto meramente ornamental, bien per $s e$ bien en relación con otros objetos con los que formara conjunto, elaborados estos últimos tanto en cerámica como en cualesquiera otras materias; que se tratara de una matriz para sellar o marcar objetos de arcilla aún tierna; que tuviera relación con el mundo de los juegos de azar y el entretenimiento; $\mathrm{o}$, finalmente, que estuviera vinculado a algún tipo de práctica mágica o adivinatoria. Todas estas alternativas vinculadas a los dados las tenemos bien documentadas en diversas culturas mediterráneas tanto de la prehistoria reciente como de la época clásica.
Sobre la primera posibilidad, y sin menospreciar el valor estético que tiene, no creemos que fuera una pieza meramente ornamental, a pesar de que se podrían interpretar las perforaciones que tiene como dispositivo para su suspensión al hacer pasar por la misma una cuerda y de este modo servir de adorno bien a otro objeto de mayores dimensiones bien simplemente a su propietario. De haber sido un elemento de adorno las aristas no necesariamente tendrían porqué estar biseladas, y si lo están creemos que es precisamente porque estaba destinado a rodar, de lo que se deriva que la decoración de cada una de las caras poseía un significado distinto para quienes la utilizaron, aunque esos significados nos resulten totalmente desconocidos. En parte relacionado con el atuendo personal y en parte con el mundo de las creencias, no debemos descartar que se tratara de un amuleto. Un amuleto, eso sí, incómodo de llevar teniendo en cuenta su volumen y peso.

A pesar de que las matrices con forma de cubo las conocemos ya desde el cuarto milenio antes de Cristo en el Próximo Oriente y, curiosamente, algunas de ellas tienen sus caras decoradas con geometrismos cuatripartitos idénticos a los que vemos en las del dado de Sepúlveda (Vollenweider, 1983, XI-XX y 47-48, no 76), la falta del más mínimo indicio de materias colorantes o de adherencias arcillosas extrañas a la pasta del propio cubo dentro de los huecos excisos dificultan el que podamos interpretarlo como objeto de carácter sigilográfico o punzón para decorar vasos cerámicos. Sería un caso único en la cultura material celtibérica que, de haber sido alguna de las dos indicadas su función, está claro que estaría destinado a dejar sus improntas sobre objetos planos, de tipo tablilla, no curvilíneos como son las paredes de los recipientes cerámicos.

Más verosimilitud que estas dos posibilidades tiene aquella otra que relaciona la pieza en cuestión con actividades de carácter lúdico, que fuera una pieza perteneciente a algún juego de azar puesto que cada cara lleva una imagen distinta y, como ya señalamos, las aristas han sido biseladas para reducir la resistencia de la pieza al libre rodamiento por el suelo. El problema es que apenas existen fuentes escritas para el conocimiento de este tipo de actividades tanto en el mundo prerromano peninsular como en el transpirenaico y los restos materiales vinculados a las mismas son poco variados: generalmente astrágalos, muy abundantes en necrópolis y poblados de la zona ibérica como, p. ej., La Alcudia de Elche (Ramos Folques, 1977), El Cigarralejo (Cuadrado, 1968, 162) o Coímbra del Barranco Ancho (Iniesta, 
Page y García, 1987, 51-52), pero también dados, realizados bien en piedra, como los hallados en Estacar de Robarinas (García-Gelabert y Blázquez, 1988, 138, fig. 41) o Baza (Presedo, 1982, 210), bien en cerámica, en hueso (p. ej., el de Coímbra del Barranco Ancho, García Cano, 1997, 251, fig. 119, 7) e incluso en madera (véase el de Cancho Roano en Celestino Pérez y Jiménez Ávila, 1993, 140, fig. 41, 1 y lám. XXV, B). En cada una de las caras de los dados hasta ahora conocidos se han consignado por regla general valores numéricos, simples puntos o anillos (sencillos o dobles) en la mayoría de los casos, pero también grafías con idénticos valores, presumiblemente (para ejemplares etruscos Krogmann, 1958, y para el único caso hispano conocido Arlegui, 1992, 485, lám. 3, 30 y Arlegui y Ballester, 1997). Ya en época romana, a estos procedimientos se añadió otro más: sílabas y palabras compuestas por tantas letras como números se quieren hacer constar en las caras (véanse, p. ej., el dado húngaro de procedencia concreta desconocida documentado en Bíró, 1994, pl. LXXVIII, 668, o el más famoso aún hallado en Autun que recogen D'Aremberg y Saglio, 1902, 127, fig. 6814).

Por más que hemos intentado identificar cada una de las representaciones realizadas en las caras del cubo sepulvedano con valores numéricos, para de ello deducir el sentido lúdico del mismo, el resultado ha sido negativo. Bien es cierto que si atendemos al número de zonas decoradas con excisión en cada cara, la D muestra cuatro, la F, cinco y la C, la del zoomorfo, seis. Sin embargo, los valores uno, dos y tres resultan imposibles de identificar a través de las decoraciones representadas en las caras A, B y E. Aun a riesgo de incurrir en una conjetura más injustificable que la anterior, podríamos ver en el doble hacha de la cara $\mathrm{B}$ el valor dos, pero ¿dónde estarían el uno y el tres?

Quizá más descaminados iríamos aún si identificásemos el zoomorfo representado en perspectiva cenital con valor uno y no seis. Si convenimos en que se trata de un cánido (lobo o perro), como indudablemente se nos muestra en algunas imágenes conocidas desde hace tiempo (p. ej., Romero Carnicero y Sanz Mínguez, 1992, 456, fig. 1, 1; Blanco García, 1997, 185, fig. 2, 1; Abarquero Moras, 2002), y reparamos en el hecho de que la tirada de dados más nefasta, aquella en la que se sacaban tres ases, recibía la denominación de "golpe de perro" (Néraudau, 1984, 299), podríamos pensar que esta figura tuviera ese valor numérico de uno. De haber sido así, cosa de la que estamos poco o nada convencidos, pues somos conscientes de que esta es una interpretación bastante forzada y tan conjetural como las anteriores, en este zoomorfo habría que ver connotaciones negativas, algo que tampoco creemos por lo que hoy sabemos de estas peculiares figuras.

Entre los muchos tipos de objetos utilizados a lo largo de la prehistoria reciente y la época clásica para adivinar la voluntad de los dioses (guijarros, habas, palos, huesos, conchas, flechas, etc., Bloch, 1985, 47-48), los dados están presentes prácticamente por todo el Viejo Mundo. No se sabe claramente en qué zona o zonas y en qué momento nace este método, pero lo cierto es que tanto en el Egipto faraónico (Luck, 1995, 289) como entre las poblaciones de las estepas de comienzos del segundo milenio antes de Cristo (VV.AA., 1993, 77) ya se hacía uso del mismo. Sabemos cómo incluso algunos santuarios, como el ático de Skiron, dedicado a Athenea Skiras, usaban exclusivamente dados para sus adivinaciones (Flacelière, 1965, 17-18). En esta labor no se empleaba un único dado, sino varios, a veces dos pero más habitualmente tres, esto es, los mismos que eran utilizados en el juego (Flacelière, 1967, 207; Guillén, 1978, 319).

Teniendo en cuenta la gran importancia que daba el mundo céltico a las actividades adivinatorias y mágicas (Marco Simón, 2002), no debemos desestimar la posibilidad de que este dado, junto con otros más, fuera una "herramienta de trabajo" de alguien relacionado con la magia, una mna bricta (mujer dotada de poderes mágicos) o un hombre. Así, cada cara sería portadora de contenidos ideológicos distintos, positivos unos y negativos otros. Al igual que para la opción anterior, constituye una importante dificultad la carencia de informaciones sobre las prácticas mágicas de las poblaciones prerromanas peninsulares y la falta de materiales arqueológicos claramente relacionados con estas actividades.

Menos problemas que la funcionalidad de este dado presenta la cuestión de la cronología, a pesar de tratarse de un hallazgo de superficie. Los restos materiales celtibéricos recuperados en el poblado ubicado en el sepulvedano Cerro de Somosierra indican que el periodo de vida del mismo se extiende desde finales del siglo $\mathrm{V}$ a. $\mathrm{C}$. o inicios del IV hasta fechas cercanas al cambio de Era, momento en el que el núcleo se deshabita (Blanco García, 1998, 164-167). Dentro de este amplio marco temporal, la iconografía desarrollada en cada una de sus caras es claramente tardía. Si exceptuamos el zoomorfo en perspectiva cenital, de cuyo extremo esquematismo no se sigue necesariamente su modernidad, el resto de los motivos decorativos pertenecen a ese sustrato 
"tardoceltibérico" (Sacristán, 1986, 239-244, láms. LXXXV-XCIII; Id., 1986-87; Sacristán y Pérez, 1986-88) en el que más tarde se inspirarían las pinturas vasculares de la cerámica denominada de Tipo Clunia o Alto Duero: metopas cruzadas por aspas sencillas y dobles, flores tetrapétalas, arcos de círculo contrapuestos, etc. (Abascal Palazón, 1986; García Merino, 1990; Blanco García, 2003, 140, fig. 36), unos motivos que, a su vez, fueron muy utilizados por los pintores ceramistas ibéricos (Tortosa, 1996, 153, fig. 76; Olmos, Tortosa e Iguácel, 1992, 126, 2). Por tanto, creemos que habría que pensar en una cronología de la segunda mitad del siglo I a. C. para esta peculiar pieza.

\section{Bibliografía}

ABARQUERO MORAS, F. J., 2002: "Un vaso singular de la 'Casa del Sótano' de Rauda (Roa de Duero, Burgos)”, Guión del Curso de la Fundación Universidad de Verano de Castilla y León Los Vacceos: Arqueología y Fuentes, dir. por F. Romero Carnicero y C. Sanz Mínguez, Abadía de Retuerta-Peñafiel, 8-11 de julio de 2002. Valladolid.

ABASCAL PALAZÓN, J. M., 1986: La cerámica pintada romana de tradición indígena. Madrid.

ARLEGUI SÁNCHEZ, M., 1992: "Las cerámicas de Numancia con letrero ibérico", en C. de la Casa (Dir.) Actas del II Symposium de Arqueología Soriana, Vol. I, 473-494. Soria.

ARLEGUI, M. A. y BALLESTER, X., 1997: "El Dado Numantino", Kalathos, 16, 213-221. Teruel.

BÉAL, J. C., 1983: Catalogue des objets de la tabletterie du Musee de la Civilisation Gallo-Romaine de Lyon. Lyon.

BÍRÓ, M. T., 1994: The bone objets of the Roman Collection. (Catalogui Musei Nationalis Hungarici. Series Archaeologica, II). Budapest.

BLANCO GARCÍA, J. F., 1997: "Zoomorfos celtibéricos en perspectiva cenital. A propósito de los hallazgos de Cauca y el castro Cuesta del Mercado (Coca, Segovia)", Complutum, 8, 183-203. Madrid.

- 1998: "La Edad del Hierro en Sepúlveda (Segovia)", Zephyrus, LI, 137-174. Salamanca.

- 2003: Cerámica histórica en la provincia de Segovia. I. Del Neolítico a época visigoda ( $V$ milenio-711 d.C.). (Trabajos de Arqueología Hispánica, 1). Segovia.

BLOCH, R., 1985: La adivinación en la Antigüedad. México.
BONET ROSADO, H., 1995: El Tossal de Sant Miquel de Llíria. La antigua Edeta y su territorio. Valencia.

CELESTINO PÉREZ, S. y JIMÉNEZ ÁVILA, F. J., 1993 : El Palacio-Santuario de Cancho Roano IV. El Sector Norte. Badajoz.

CENTENO, I., SANZ, C., VELASCO, J. y GARRIDO, A. I., 2003: "Aproximación al urbanismo vacceoromano de Pintia", en C. Sanz y J. Velasco (Eds.) Pintia. Un Oppidum en los Confines Orientales de la Región Vaccea. Investigaciones Arqueológicas Vacceas, Romanas y Visigodas (1999-2003), 69-98. Valladolid.

CUADRADO, E., 1968: "Tumbas principescas de El Cigarralejo", Madrider Mitteilungen, 9, 148-186. Heidelberg.

DAREMBERG, CH. et SAGLIO, M. E., 1883-1919: Dictionnaire des Antiquités Grecques et Romaines. T. V. París.

DELIBES, G. y ESPARZA, A., 1989: "Los tesoros prerromanos de la Meseta Norte y la orfebrería celtibérica”, en El Oro en la España Prerromana (Revista de Arqueología, Extra 4), 108-129. Madrid.

FLACELIÈRE, R., 1965: Greek Oracles. London.

- 1967: La vie quotidienne en Grèce au siècle de Péricles. París.

GARCÍA CANO, J. M., 1997: Las necrópolis ibéricas de Coímbra del Barranco Ancho (Jumilla, Murcia). Las excavaciones y estudio analítico de los materiales. Murcia.

GARCÍA GELABERT, M. P. y BLÁZQUEZ MARTÍNEZ, J. M., 1988: Cástulo. Jaén, España. Excavaciones en la necrópolis ibérica del Estacar de Robarinas (s. IV a. C.). (BAR Int. Ser., 425). Oxford.

GARCÍA MERINO, C., 1990: "Algunas consideraciones sobre la cerámica celtibérica pintada y su evolución hacia la pintada de época imperial: el caso de Uxama", AEspA, 63, 115-135. Madrid.

GREEN, M. J., 1989: Symbol and Image in Celtic Religious Art. London \& New York.

- 1997: Dictionary of Celtic Myth and Legend. London.

GUILLÉN, J., 1978: Urbs Roma. Vida y costumbres de los romanos. II, La vida pública. Salamanca.

INIESTA, A., PAGE, V. y GARCÍA, J. M., 1987: Excavaciones arqueológicas en Coimbra del Barranco Ancho, 1. Jumilla. Sepultura 70 de la necrópolis del poblado. Murcia.

KROGMANN, W., 1958: "Die etruskischen Zahlwörter von 'eins' bis 'sechs', Glotta, 37, 150-160. (Reprint 1991). Göttingen. 
LUCK, G., 1995: Arcana Mundi. Magia y ciencias ocultas en el mundo griego y romano. Madrid.

MARCO SIMÓN, F., 2002: "Magia literaria y prácticas mágicas en el mundo romano-céltico”, en A. Pérez Jiménez y G. Cruz Andreotti (Eds.) Daímon Páredros: Magos y Prácticas mágicas en el Mundo Mediterráneo, (Mediterránea, 9), 189-219. Madrid.

NÉRAUDAU, J.-P., 1984: Etre enfant a Rome. París.

OLMOS, R., TORTOSA, T. e IGUÁCEL, P., 1992: "La creación de una narrativa", en La Sociedad Ibérica a través de la Imagen, 117-154. Barcelona.

PRESEDO, F. J., 1982: La necrópolis de Baza, (EAE, 119). Madrid.

PY, M., 1990: Culture, Économie et Société Protohistoriques dans la Région Nimoise. (Collection de l'École Française de Rome, 131). Roma.

RAMOS FOLQUES, A., 1977: “Tabas y dados”, XIV CNA, 767-768. Zaragoza.

ROMERO CARNICERO, F. y SANZ MÍNGUEZ, C., 1992: "Representaciones zoomorfas prerromanas en perspectiva cenital. Iconografía, cronología y dispersión geográfica", en C. de la Casa (Dir.) II Symposium de Arqueología Soriana, vol. I, 453-471. Soria.

SACRISTÁN, J. D., 1986: La Edad del Hierro en el Valle Medio del Duero. Rauda (Roa, Burgos). Valladolid.
- 1986-87: "Sobre la formación de los conjuntos cerámicos tardoceltibéricos”, Zephyrus, XXXIX-XL, 179183. Salamanca.

SACRISTÁN, J. D. y PÉREZ, F., 1986-88: "Un interesante conjunto cerámico tardoceltibérico", Sautuola, V, 81-113. Santander.

SANZ MÍNGUEZ, C., 1997: Los Vacceos: cultura y ritos funerarios de un pueblo prerromano del valle medio del Duero. La necrópolis de Las Ruedas, Padilla de Duero (Valladolid). (Arqueología en Castilla y León, Memorias, 6). Salamanca.

TORTOSA, T., 1996: "Imagen y símbolo en la cerámica ibérica del Sureste", en R. Olmos (Ed.) Al Otro Lado del Espejo. Aproximación a la Imagen Ibérica, 145-162. Madrid.

VOLLENWEIDER, M.-L., 1983: Catalogue Raisonné des Sceaux, Cylindres, Intailles et Camées. Vol. III, La Collection du Révérend Dr. V.E.G. Kenna et dautres acquisitions et dons récents, (Musée d'Art et d'Histoire de Genève), Mainz am Rhein.

VV.AA., 1993: Gold aus Kiev. Wien.

WATTENBERG SANPERE, F., 1963: Las cerámicas indígenas de Numancia, (Bibliotheca Praehistorica Hispana, IV). Madrid. 